\title{
Increasing prevalence of ESBL-producing Enterobacteriaceae in Sudan community patients with UTIs
}

\author{
Omar B. Ahmed ${ }^{1}$, Alfadel O. Omar ${ }^{2}$, Atif H. Asghar ${ }^{1}$, Mogahid M. Elhassan ${ }^{3 \& 4}$ \\ 1- Department of Environmental and Health Research, The Custodian of the Two Holy \\ Mosques Institute for Hajj and Omraa. Umm Alqura University, Makkah, Kingdam \\ of Saudi Arabia. \\ 2- College of Medical Laboratory Science, Al Nilain University, Khartoum, Sudan. \\ 3- Department of Medical Laboratory Technology, College of Applied Medical \\ Sciences, Taibah University, Al Madena Al Monawarah, KSA. \\ 4- Department of Microbiology, College of Medical Laboratory Science, Sudan \\ University of Science and Technology, Khartoum, Sudan. \\ Email: mogahidelhassan@yahoo.com.
}

\begin{abstract}
Three hundred and thirty two $(\mathrm{n}=332)$ urine specimens were collected from patients attending different hospitals in Khartoum State during the period from May to November 2011. The isolates were transported to the microbiology lab (research lab) at Sudan University for Sciences and Technology. Identification of isolates was done by using conventional biochemical methods and microbact 2000 24E (OXOID) system. All Isolates were then stored at $-70^{\circ} \mathrm{C}$ in Tryptic Soy broth with $20 \%$ glycerol. The isolated bacteria were tested for their antimicrobial resistance. ESBL screening was confirmed by double disk synergy test. The results showed that urinary Gram negative bacteria was $65.7 \%$. High rate was caused by E. coli $(72.0 \%)$ followed by $K$. pneumoniae (14.7\%). Maximum sensitivity was seen for imipenem (100\%), followed by piperacillin/tazobactum $(91.7 \%)$ and cefoxitin $(87.2 \%)$. The maximum resistance was seen against ceftazidime $(74.8 \%)$ followed by cefotaxime $(70.6 \%)$. ESBL producing bacteria was (59.6\%) mostly were in K. pneumoniae (68.8.\%) followed by E. coli $(65.0 \%)$. ESBL producing bacteria showed maximum resistance to ceftazidime $(95.4 \%)$, followed by cefotaxime $(94.6 \%)$, while minimum resistance was seen with imipenem $(0 \%)$, followed by piperacillin/tazobactam $(3.8 \%)$ and cefepime $(7.7 \%)$.
\end{abstract}

\section{INTRODUCTION}

Bacteria that have become resistant to antibiotic drug therapy are an increasing public health problem. Urinary tract infections (UTIs), are just a few of the diseases that have become hard to treat with antibiotics. UTIs are of the most common bacterial infections in the general population, with an estimated overall incidence rate of 18 per 1000 person per year. In addition, UTIs are major cause of hospital admissions and are associated with significant morbidity and mortality as well as a high economic burden. (Bader et al. 2010).

Members of Enterobacteriaceae, specifically, E. coli, are the main causes of UTIs. Staphylococcus saprophyticus (Staph. saprophyticus) is the second most common cause, and lesser percent are caused by other Enterobacteriaceae such as Proteus and Klebsiella or by Enterococcus or by Pseudomonas species (Nicolettia et al., 2010). Sulfamethoxazole, ciprofloxacin, cephalosporins, semi-synthetic penicillins with or without inhibitors, gentamycin, amikacin, nitrofurantoin and fosfomycin are the most commonly used antibacterial drugs in the UTIs treatment (Rasoul et al., 2009).

One of UTI complications is the emergence of antibiotic-resistant strains. Inadequate empiric antibacterial therapy 
has been associated with increased mortality rates in patients with UTIs. Other reasons include treatment failure and prolonged therapy with antimicrobial agents. Moreover, patients who enter hospitals for the treatment of resistant bacterial infections or acquire resistant infections while in the hospital are adding to the already too high costs of healthcare and are a source of resistant bacteria and/or resistance-encoding genes (Haber et al., 2010). In the last 10 years, many kinds of resistant strains have been found in UTIs. For instance, methicillinresistant Staphylococcus aureus (MRSA), multidrug-resistant Pseudomonas aeruginosa (MDRP), multidrug-resistant Serratia marcesence, vancomycin-resistant enterococci (VRE)and extended-spectrum betalactamase (ESBL)-producing strains have been reported (Bader et al., 2010).

Extended-spectrum beta-lactamases (ESBLs) are plasmid-associated or chromosomally encoded beta lactamases that have recently been found in the Enterobacteriaceae. (Song et al., 2012). ESBLs are capable of hydrolyzing penicillins, many narrow spectrum cephalosporins, many extended-spectrum cephalosporins, oxyimino-cephalosporins (cefotaxime, ceftazidime), and monobactams (aztreonam). Betalactamase inhibitors (e.g. clavulanic acid) generally inhibit ESBL producing strains. Identifying ESBL-producing organisms is a major challenge for the clinical microbiology laboratory. Diskdiffusion and dilution methods are useful methods for screening of ESBL production by Enterobacteriaeae. Proper infection-control practices and barriers are essential to prevent spreading and outbreaks of ESBL-producing bacteria (Langford et al. 2011).

\section{MATERIALS AND METHODS}

The study was carried out using 332 urinary bacterial isolates collected at different hospitals in Khartoum State during 6 months (May to November) 2011. The distribution of all 332 positive UTI cases collected from different hospitals in Khartoum state. The desired patient information were obtained from each patient and recorded in a special request form. The isolates were collected in nutrient broth media and transported to the microbiology lab (research lab at Faculty of Medical Lab Sciences) Sudan University for Sciences and Technology (SUST).

To obtain pure culture, isolates were subcultured in Cysteine Lactose Electrolyte Deficient (CLED) agar and nutrient Agar, then identification of isolates was done by using conventional and biochemical methods. Identification of Gram negative isolates was based on Gram staining, oxidase test and microbact 2000 24E (OXOID) system. After identification, all isolates were stored at $-70^{\circ} \mathrm{C}$ in Tryptic Soy broth with $20 \%$ glycerol until antibiotic susceptibility test was performed. All the isolated bacteria were tested for their antimicrobial resistance to various antibiotics in vitro by the Kirby-Baur disk diffusion method. The tested were ceftazidime (CAZ) $(30 \mu \mathrm{g})$, Cefotaxime (CTX) $(30 \mu \mathrm{g})$, Norfloxacin (NOR) (10) amikacin (AK) $(30 \mu \mathrm{g})$, Ceftriaxone (CRO) $\quad(30 \mu \mathrm{g}), \quad$ Co-trimoxazole $(\mathrm{SXT})(1.25 / 23.75 \mu \mathrm{g}), \quad$ Azithromycin (AZM) (15), nitrofurantoin (NF) (300) $\mu \mathrm{g}$ ), cefoxitin (FOX) (30), piperacillin (PIP) (100), cefepime (FEB) (30), piperacillin/tazobactum (TZP) $(100 / 10)$, amoxyclav (AMC) (20/10), Imipenam (IPM) (10) and Tetracycline (TE) (30 $\mu \mathrm{g})$. Plates were incubated at $37^{\circ} \mathrm{C}$ overnight. After overnight incubation, the diameter of each zone of inhibition was measured in $\mathrm{mm}$. The susceptibility testing results were recorded according to the Clinical and Laboratory Standards Institute (CLSI) guidelines (CLSI, 2001). The isolates were tested for their susceptibility to the third generation cephalosporins ceftazidime $(30 \mu \mathrm{g})$, 
cefotaxime $(30 \mu \mathrm{g})$, ceftriaxone $(30 \mu \mathrm{g})$ and aztreonam $(30 \mu \mathrm{g})$ by using the standard disc diffusion method, as was recommended by the CLSI (CLSI, 2001). ESBL were screened by detection reduced zones of inhibition around third generation cephalosporins. The strain was considered to be "suspicious for ESBL production" (CLSI, 2001). If zone diameter of ceftazidime, $<22 \mathrm{~mm}$, cefotaxime, $<27 \mathrm{~mm}$, ceftriaxone, $<25$ $\mathrm{mm}$ and aztreonam, $<27 \mathrm{~mm}$. Only those isolates which were resistant to one of the third generation cephalosporins were selected for the study and they were processed for the ESBL production.

ESBL confirmation was done by double disk synergy test (DDST) as described by Jarlier et al., (1988). Isolates were inoculated on $\mathrm{MH}$-agar plates. Discs containing respectively ceftazidime $(30 \mu \mathrm{g})$, cefotaxime $(30 \mu \mathrm{g})$, ceftriaxone $(30 \mu \mathrm{g})$ and aztreonam $(30$ $\mu \mathrm{g}$ ) were placed $20 \mathrm{~mm}$ (center to center) away from a disc containing a 20 $\mu \mathrm{g}$ amoxicillin $/ 10 \mu \mathrm{g}$ clavulanic acid before overnight incubation at $37^{\circ} \mathrm{C}$. ESBL production was considered positive when the clavulanate mediated enhancement of the activity of an indicator drug produced a keyhole effect and regarded as a phenotypic confirmation for the presence of ESBL (Jarlier et al., 1988). The quality assurance was performed weekly using K. pneumoniae American type culture collection (ATCC) 700603 (ESBL producing isolate) and E. coli ATCC 25922 (susceptible isolate) as positive and negative controls, respectively.

\section{RESULTS}

The present study showed the antibiotic resistance patterns phenotyping and ESBL genotyping of the uropathogens in Khartoum. The total number of isolates was 332. The total number of GP bacteria (cocci) was $114(34.3 \%)$ while the total number of GN bacteria (bacilli) was $218(65.7 \%)$. (Table 1) shows the frequency of GNB collected. high rate of UTIs was caused by E. coli $(72.0 \%)$ followed by $K$. pneumoniae $(14.7 \%)$, while less rate was caused by Enterobacter spp (1.4\%) followed by $K$. oxycota $(3.2 \%), P$. mirablis (4.1\%) and Ps. aeruginosa (4.6 $\%)$. In this study, ESBL producing bacteria were $130 \quad(59.6 \%)$ The nonESBL producers bacteria were 88 (40.4\%) (Table 1, Fig. 1 \&Fig. 2).

Table 1: Frequency of Gram negative and ESBL producers among study subjects.

\begin{tabular}{|l|c|c|}
\hline \multicolumn{1}{|c|}{ Bacterial isolate } & Total \% & ESBL \% \\
\hline E. coli & $72.0(157)$ & $65.0(102)$ \\
\hline K. pneumonia & $14.7(32)$ & $68.8(22)$ \\
\hline K. oxycota & $3.2(07)$ & $28.6(02)$ \\
\hline P. mirablis & $4.1(09)$ & $33.3(03)$ \\
\hline Ps. aeruginosa & $4.6(10)$ & $10(01)$ \\
\hline Enterobacter spp & $1.4(03)$ & 0.0 \\
\hline Total & $100(218)$ & $(130)$ \\
\hline
\end{tabular}

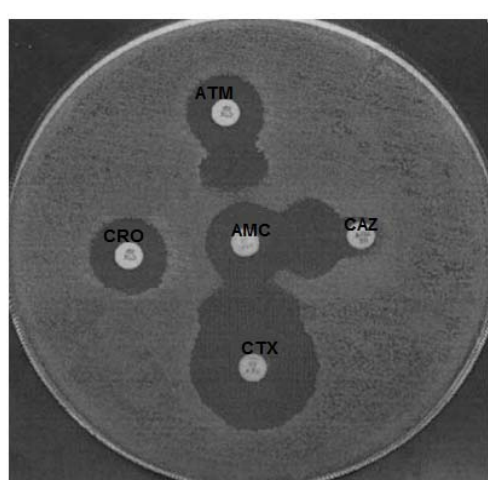

Fig. 1: Double disk synergy of ESBL producers on Muller Hinton Agar after overnight incubation.

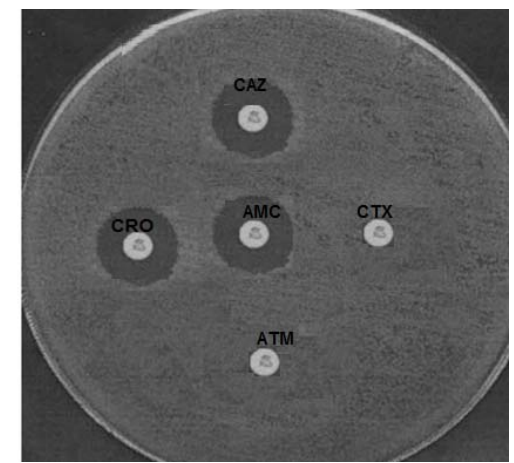

Fig. 2: Negative ESBL isolates on Muller Hinton Agar after overnight incubation 
Antibiotic susceptibility pattern of GN bacilli (218) and antibacterial resistance of ESBL and non-ESBL producing bacteria among urinary isolates are shown in (Table 2). The antibiotic sensitivity pattern of the GN isolates revealed that the maximum sensitivity was seen for imipenem $(100 \%), \quad$ followed by piperacillin/tazobactum (91.7\%), cefoxitin $(87.2 \%)$, amikacin $(67.4 \%)$ and nitrofurantoin $(59.2 \%)$. The maximum resistance was seen against ceftazidime (74.8\%), cefotaxime $(70.6 \%)$, and both cefipime and ceftriaxone were $(67.0 \%)$. ESBL phenotype producing bacteria showed maximum resistance to ceftazidime $(95.4 \%)$, followed by cefotaxime $(94.6 \%)$ and ceftriaxone
(94.0\%) while minimum resistance was seen with imipenem $(0 \%)$, followed by piperacillin/tazobactam (3.8\%) and cefepime $\quad(7.7 \%)$. The non-ESBL phenoype producing bacteria showed maximum resistance to co-amoxiclav $(60.2 \%)$ followed by cefipime (48.9\%), ceftazidime $(44.3 \%)$ pipracillin, and tetracycline $(39.8 \%)$ while the minimum resistance was seen with imipenem $(0 \%)$,followed by piperacillin/tazobactam (3.4\%), cefoxitin $(5.7 \%)$, azithromycin $(16.0 \%)$ and nitrofurantoin $(17.0 \%)$. The maximum number of ESBL phenotype producers was seen in $K$. pneumoniae (68.8.\%) followed by E. coli (65.0\%), Proteus spp $33.3 \%$, K. oxycota $28.6 \%$ and Ps. aeruginosa $10.0 \%$ as shown in (Table 1).

Table 2: Antibiotic susceptibility pattern of Gram negative bacilli and antibacterial resistance of ESBL and non-ESBL producers.

\begin{tabular}{|c|c|c|c|c|c|c|}
\hline & Antibiotic Name & Sensitive & Inermediate $\%$ & \multicolumn{3}{|c|}{ Resistant \% } \\
\cline { 5 - 6 } & & & & ESBL(130) & NONESBL(88) & All(218) \\
\hline 1 & AK & $67.4(147)$ & $2.3(5)$ & $38.5(50)$ & $18.2(16)$ & $30.3(66)$ \\
\hline 2 & IPM & $100.0(218)$ & $0.0(4)$ & $0(0)$ & $0 .(0)$ & $0.0(0)$ \\
\hline 3 & FOX & $87.2(190)$ & $4.6(11)$ & $14.8(13)$ & $5.7(5)$ & $8.3(18)$ \\
\hline 4 & CAZ & $16.5(36)$ & $8.9(19)$ & $95.4(124)$ & $44.3(39)$ & $74.8(163)$ \\
\hline 5 & PIP & $31.2(68)$ & $6.8(15)$ & $77.0(100)$ & $39.8(35)$ & $62.0(135)$ \\
\hline 6 & AZM & $53.2(116)$ & $15.1(33)$ & $42.3(55)$ & $16.0(14)$ & $31.2(69)$ \\
\hline 7 & CRO & $15.6(34)$ & $17.4(38)$ & $94.0(122)$ & $27.3(24)$ & $67.0(146)$ \\
\hline 8 & CTX & $20.6(45)$ & $8.7(19)$ & $94.6(123)$ & $35.2(31)$ & $70.6(154)$ \\
\hline 9 & TZP & $91.7(200)$ & $4.6(10)$ & $3.8(5)$ & $3.4(3)$ & $3.7(8)$ \\
\hline 10 & FEP & $29.4(64)$ & $3.7(8)$ & $79.2(103)$ & $48.9(43)$ & $67.0(146)$ \\
\hline 11 & NF & $59.2(129)$ & $13.3(29)$ & $34.6(45)$ & $17.0(15)$ & $27.5(60)$ \\
\hline 12 & SXT & $35.3(77)$ & $16.5(36)$ & $67.7(88)$ & $19.3(17)$ & $48.2(105)$ \\
\hline 13 & TE & $24.8(54)$ & $28.4(62)$ & $51.5(67)$ & $39.8(35)$ & $47.0(102)$ \\
\hline 14 & AMC & $37.6(82)$ & $19.3(42)$ & $31.5(41)$ & $60.2(53)$ & $43.1(94)$ \\
\hline 15 & NOR & $45.4(99)$ & $31.2(68)$ & $26.2(34)$ & $19.3(17)$ & $23.4(51)$ \\
\hline
\end{tabular}

\section{DISCUSSION}

Worldwide Gram negative bacteria account for more than $80 \%$ of the culture positive cases of UTIs and 10 to $20 \%$ are caused by coagulase-negative: $S$. saprophyticus and 5 percent or less are caused by other enterobacteriaceae such as Proteus and Klebsiella or by Enterococcus species (Nicolettia et al., 2010; Shaifali 2012). In this study, the total number of Gram positive bacteria (cocci) was $34.3 \%$ while the total number of Gram negative bacteria (bacilli) was $65.7 \%$. The Gram negative bacilli predominated, with E. coli being the most common pathogen isolated in the study. As shown in (Table 1), high rate of UTIs was caused by E. coli $72.0 \%$ followed by K. pneumoniae $14.7 \%$ while less rate was caused by Enterobacter spp $1.4 \%$ followed by $K$. oxycota $3.2 \%$, P. mirablis $4.1 \%$ and Ps. aeruginosa $4.6 \%$. Other studies had also reported a similar frequency of UTI caused by $E$. 
coli. (Sabharwal 2012; Okonko et al., 2009).

The antibiotic sensitivity pattern of the Gram negative bacteria (Table 2) revealed that the maximum sensitivity was seen for imipenem (100\%), followed by piperacillin/tazobactum $91.7 \%$, cefoxitin $87.2 \%$, amikacin $67.4 \%$ and nitrofurantoin $59.2 \%$. Similarly, in a study from India, most members of GN bacilli were found to be susceptible to imipenem (95.1\%) and piperacillin/tazobactum $71.8 \%$ (Dalela et al., 2012). Dalela et al. also found that sensitivity of cefoxitin was $79.6 \%$ which is near to this study.

In this study, low resistance was shown to norfloxacin $23.4 \%$ by almost most of the isolates. Norfloxacin, showed a low resistance in comparison with other studies which found higher rates (Keah et al., 2007; Akram et al., 2007 and Manjunath et al., 2011).

Among other oral antibiotics, nitrofurantoin was found to have (40\%) resistance in the present study. Sabharwal found low resistance rate $10 \%$ to nitrofurantoin while Akram et al, found a very high resistance rate $(80 \%)$ to nitrofurantoin in patients with community acquired UTI (Akram et al., 2007). The consistent and high-level susceptibility of GN isolates to nitrofurantoin may be influenced by nitrofurantoin's narrow spectrum of activity, limited indication (treatment of acute cystitis), narrow tissue distribution (low or undetectable serum concentrations), and limited contact with bacteria outside the urinary tract (Bean et al., 2008; Karlowsky et al., 2002).

The alarming finding in this study is the resistance to third generation cephalosporin,. Maximum resistance was seen against ceftazidime $74.8 \%$, cefotaxime $70.6 \%$ and $67.0 \%$ against both cefipime and ceftriaxone.

The possible explanation behind the resistance showed to these antibiotics, may be because these antibiotics have been in use for a long period and must have been abused and as a result the organisms must have developed mechanisms of changing their mode of action. The inappropriate and empirical usage of wide spectrum antibiotics, insufficient hygiene, immunosuppression and a prolonged stay in the hospital are some of the major aetiological factors that elevate the chances of MDR infections (Manjunath et al., 2011).

In this study, ESBL phenotypes were found positive in $130(59.6 \%)$ of the isolates and confirmed by (DDST) method while negative (non-ESB) phenotype were $40.4 \%$. A report from 10 European countries showed that the prevalence of ESBL-producing E. coli and $K$. pneumoniae ranged from at least $1.5 \%$ in Germany and 39 to $47 \%$ in Russia, Poland and Turkey (Goosens 2001). ESBL production which was reported among Gram negative bacteria by Mekki et al from Sudan, Dalela et al from India and Ozcakar et al from Turkey (Ozcakar et al., 2011) is in agreement with that which was found in this study.

Among the isolated bacteria, the most prevalent ESBLs belonged to Klebsiella $68.8 \%$ and E. coli $65.0 \%$. While the minimum number was seen in Ps. aeruginosa $(10.0 \%)$ followed by $K$. oxycota $28.6 \%$ and Proteus spp $33.3 \%$, In Sudan, Mekki et al. reported ESBL producing as $53 \%$ from the UTIs patients in Khartoum. Also in a study from India, nearly $40 \%$ urinary isolates of $E$. coli and $K$. pneumoniae were ESBL positive (Babypadmini and Appalaraju, 2004). ESBL producing $K$. pneumoniae were $54.4 \%$ in a study from Latin America (Aminzadeh et al., 2008). Ejaz et al found the ESBL producing $E$. coli and $K$. pneumoniae were 57.4 and $71.7 \%$, respectively (Ejaz et al., 2011). In another study conducted in Pakistan, $56.9 \%$ isolates of E. coli were ESBL positive (Ullah et al., 2009). 
The majority of ESBL producing bacteria were resistant to the common antibiotics used in the treatment of UTIs. In the present study, ESBL producing Gram negative bacteria were found to be multidrug resistant. In ESBL producing bacteria, high percentage of antibacterial resistance than non-ESBL antibiotics which is a serious matter of concern. Recent studies revealed that patients with ESBL producing organisms had significantly higher fatality rate than those with non-ESBL isolates (Mehrgan and Rahbar 2008, Ejaz et al., 2011, ).

ESBL producing bacteria showed no resistance to imipenem $(0 \%)$, and low resistance to piperacillin/tazobactam (3.8\%) and cefoxitin (14.8\%) and higher resistance was seen against ceftazidime (95.4\%) cefotaxime $(94.6 \%)$, and ceftriaxone $(94.0 \%)$. In similar study in Khartoum, Mekki et al, found that all the isolates were $100 \%$ susceptible for imipenem and both Pipracillin/tazobactum and cefipime showed a good activity $(74.05 \%)$ and $(97.09 \%)$ respectively (Mekki et al., 2010), which is in agreement with this study, but Mekki et al found that there were a high resistance pattern for cefoxitin $(100 \%)$ which disagree to the finding of this study. In a study from Rawalpindi, Roshan et al concluded that antibiotic choices in case of ESBL producing isolates are limited and at present only carbapenems can be regarded as treatment of choice (Roshan et al., 2011).

Therefore, imipenem is the most active drug for the treatment of MDR infections especially that caused by the ESBL producers, followed by piperacillin/ tazobactum and cefoxitin. The heavy use of carbapenem, can lead to the growth of Stenotrophomonas maltophilia (a species which is naturally resistant to these drugs ( Luzzaro et al., 2006).

Generally there is a need for continuous monitoring systems and effective infection control measures to prevent the rapid and worldwide spread of these MDR infections. Monitoring of ESBL production and antimicrobial susceptibility testing are necessary to avoid treatment failure in patients with UTI. ESBL producers are associated with increased morbidity and mortality. The early detection and reporting of suitable antibiotics can reduce the treatment failure in ESBL regarding UTI.

\section{REFERENCES}

Akram M, Shahid M, Khan AU (2007). Etiology and antibiotic resistance patterns of community-acquired urinary tract infections in the JNMC Hospital Aligarh, India. Ann Clin Microbiol Antimicrob 6:4.

Aminzadeh Z, Sadat KM, Shabani M (2008). Bacteriuria by extended spectrum Beta-lactamase-producing E. coli and Klebsiella pneumoniae: isolates in a governmental hospital in South of Tehran, Iran. Iran J. Kidney Dis. 2(4): 197-200.

Babypadmini S, Appalaraju B (2004). Extended spectrum lactamase in urinary isolates of $E$. coli and Klebsiella pneumoniae-prevalence and susceptibility pattern in a Tertiary care hospital. Indian J. Med. Microbiol. 22: 172-174.

Bader MS, Hawboldt J, Brooks A (2010). Management of complicated urinary tract infections in the era of antimicrobial resistance. Postgrad Med. 122(6):7-15.

Bean D C, Krahe D and Wareham D $\mathrm{W}(2008)$. Antimicrobial resistance in community and nosocomial Escherichia coli urinary tract isolates, London 2005 - 2006. Annals of Clinical Microbiology and Antimicrobials. 7:13.

Clinical and Laboratory Standards Iinstitute (2001). Performance standards for antimicrobial susceptibility testing. Twentieth informational supplement ed. CLSI 
document M100-S20. W24- Goosens H. MYSTIC programme: summary of European data from 1997 to 2000. Diagn. Microbiol. Infect. Dis. 41:183-189.

Dalela G, Gupta S, Jain D K, Mehta P (2012). Antibiotic Resistance Pattern in Uropathogens at a Tertiary Care Hospital at Jhalawar with Special Reference To Esbl, AmpC bLactamase and Mrsa Production. J Clin D R. 6(4):645-651.

Ejaz H, Haq I, Zafar A, Mahmood S and Javed M M. Urinary tract infections caused by extended spectrum $\beta$ lactamase (ESBL) producing Escherichia coli and Klebsiella pneumoniae. Afr. J. Biotechnol. 2011;10(73):16661-16666.

Goosens H (2001). MYSTIC programme: summary of European data from 1997 to 2000. Diagn. Microbiol. Infect. Dis. 41:183-189.

Haber M, Levin BR, and Kramarz P (2010) Antibiotic control of antibiotic resistance in hospitals: a simulation study. BMC Infect Dis. 10: 254.

Jarlier, V., Nicola, M. H., Fournier, G. \& Philippon, A (1988). Extended broadspectrum $\beta$-lactamases conferring transferable resistance to newer $\beta$ lactam agents in Enterobacteriaceae: hospital prevalence and susceptibility patterns. Rev Infect Dis.10, 867-878.

Karlowsky J A. , Kelly L J., Thornsberry C , Jones M E. , Sahm D F (2002). Trends in Antimicrobial Resistance among Urinary Tract Infection Isolates of Escherichia coli from Female Outpatients in the United States Antimicrob Agents Chemother. 46(8): 2540-2545.

Keah SH, Wee EC, Chng KS, Keah KC (2007). Antimicrobial susceptibility of community acquired uropathogens in the general practice. Malaysian Family Physician. 2:64-69.

Langford D, Williams V (2011). What does ESBL mean, and why does my patient require contact isolation? Crit Care Nurs Q. 34(1):46-51.

Luzzaro F, Mezzatesta M, Mugnaioli C, Perilli M, Stefani S, et al (2006). Extended-Spectrum $\quad \beta$-lactamases among enterobacteria of medical interest: Report of the Second Italian Nationwide Survey. J Clin Microbiol. 44(5):16059-64.

Manjunath GN, Prakash R, Annam V, Shetty K (2011). The changing trends in the spectrum of the antimicrobial drug resistance pattern of uropathogens which were isolated from hospitals and community patients with urinary tract infections in Tumkur and Bangalore. Int J Biol Med Res. 2(2):504-50.

Mehrgan H, Rahbar M (2008). Prevalence of extended-spectrum betalactamase-producing Escherichia coli in a tertiary care hospital in Tehran, Iran. Int. J. Antimicrob. Agent. 31: 1471-1451.

Mekki A H, Hassan A N, Elsayed D M (2010) Extended Spectrum Beta Lactamases Among Multi Drug Resistant Escherichia Coli and Klebsiella Species Causing Urinary Tract Infections In Khartoum J Bact Res. 2(3):18-21.

Nicolettia J, Kustera S, Sulserb T, Zbindenc R, Ruefa C, Ledergerbera B , Webera R (2010). Risk factors for urinary tract infections due to ciprofloxacin-resistant Escherichia coli in a tertiary care urology department in Switzerland. Swiss Med Wkly. 140:13059.

Okonko IO, Ijandipe LA, IIusanya AO, Donbraye-Emmanuel OB, Ejembi J, Udeze AO, et al (2009). Incidence of urinary tract infection (UTI) among pregnant women in Ibadan, southwestern Nigeria. Afr $\mathrm{J}$ Biotech. 8:6649-57.

Ozçakar ZB, Yalçınkaya F, Kavaz A, Kadioğlu G, Elhan AH, Aysev D, Güriz H, Ekim M (2011). Urinary tract infections owing to ESBL- 
producing bacteria: microorganisms change--clinical pattern does not. Acta Paediatr. 100(8):61-4.

Rasoul Y, Hooshang B, Javad Y (2009). Urinary Tract Infections: Bacteriology and Antibiotic Resistance Pattern. Ind Ped. 4:617-620.

Roshan M, Ikram A, Mirza IA, Malik N, Abbasi SA, Alizai SA (2011). Susceptibility pattern of extended spectrum $\beta$-lactamase producing isolates in various clinical specimens. J Coll Physicians Surg Pak. 21(6):342-6.

Song W, Kim J, Bae IK, Jeong SH, Seo YH, Shin JH, Jang SJ, Uh Y, Shin JH, Lee MK, Lee K (2012). Chromosome-Encoded AmpC and CTX-M Extended-Spectrum \{beta $\}$ -
Lactamases in Clinical Isolates of Proteus mirabilis from Korea. Antimicrob Agents Chemother. 55(4):1414-1419.

Sabharwal E R (2012). Antibiotic Susceptibility Patterns of Uropathogens in Obstetric Patients. N Am J Med Sci. 4(7): 316-319.

Shaifali I., Gupta U., Mahmood S E., Ahmed J (2012). Antibiotic susceptibility patterns of urinary pathogens in female outpatients. N A J Med Sci. 4(4)163-16.

Ullah F, Malik SA, Ahmed J (2009). Antibiotic susceptibility pattern and ESBLs prevalence in nosocomial Escherichia coli from urinary tract infections in Pakistan. Afr. J. Biotechnol. 8: 3921-3926.

\section{ARABIC SUMMARY}

$$
\begin{aligned}
& \text { زيادة انتثار البكتيريا المعوية المنتجة لإنزيم البيتا لاكتيميز ممتدة الطيف لاي مرضي التهابات المجاري } \\
& \text { البولية في المجتمع السوداني الانيز } \\
& \text { عمر بشير أحمد1 ، الفاضل العبيد عمر²، عاطف حسين أصغر 1، مجاهد محمد الحسن } 3
\end{aligned}
$$

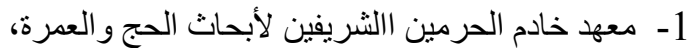

$$
\begin{aligned}
& \text { قسم البحوث الصحية و البيئية، جامعة أم القرى، مكة المكرئة المكرمة، المملكة العربية السعودية. }
\end{aligned}
$$

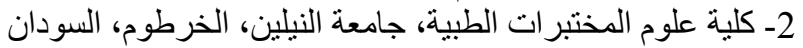

$$
\begin{aligned}
& \text { 3- قسم تقنية المختبر ات الطبية، كلية العلوم الطبية التطبيقية،جامعة طيبة، الددينة المنورة، المملكة العربية السعودية. }
\end{aligned}
$$

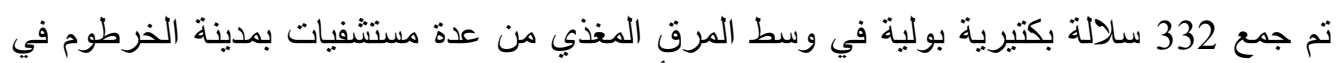

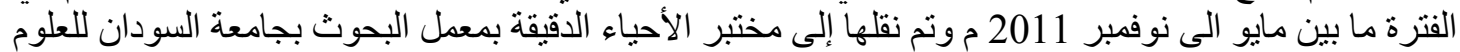

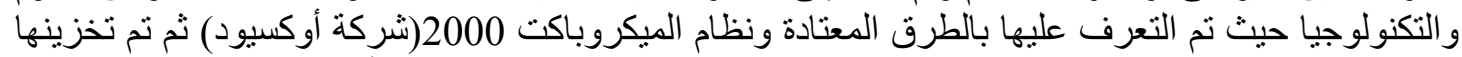

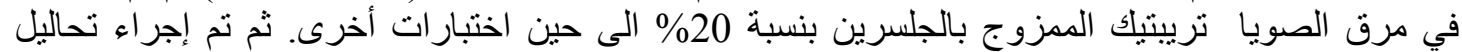

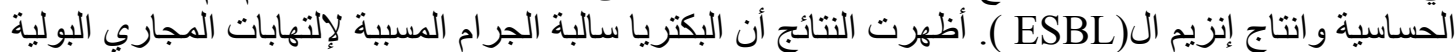

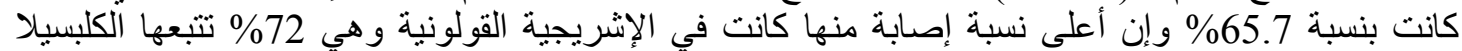

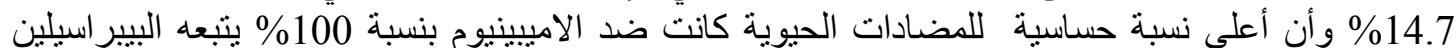

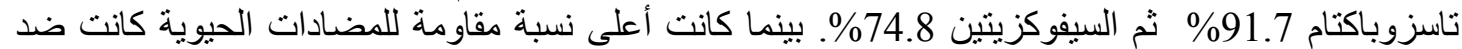

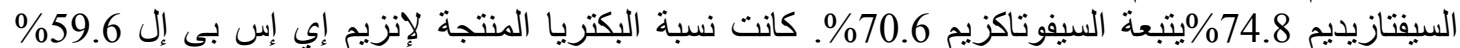
أكثرها الكلبسيلا 68.8\% تتبعها الإشريجية القولونية 65\% \% \%

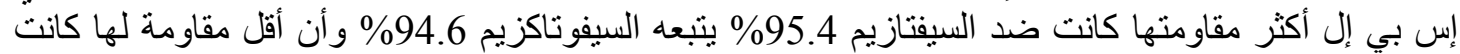
ضد الإميينيوم 0\% يتبعه الببر اسيلين تازوباكتام 3.8\% ثم السيفيبيايم بنسبة 75.7\% 